\title{
Main thoracic curve adolescent idiopathic scoliosis: association of higher rod stiffness and concave-side pedicle screw density with improvement in sagittal thoracic kyphosis restoration
}

\author{
*Hui Liu, MD, PhD, Zemin Li, MD, Sibei Li, MD, Kuibo Zhang, MD, PhD, Hao Yang, MD, \\ Jianru Wang, MD, Xiang Li, MD, and Zhaomin Zheng, MD, PhD \\ Department of Spine Surgery, The First Affiliated Hospital, Sun Yat-sen University, Guangzhou, China
}

OBJECT The aim of this study was to evaluate the effects of rod stiffness and implant density on coronal and sagittal plane correction in patients with main thoracic curve adolescent idiopathic scoliosis (AIS).

METHODS The authors conducted a retrospective study of 77 consecutive cases involving 56 female and 21 male patients with Lenke Type 1 main thoracic curve AIS who underwent single-stage posterior correction and instrumented spinal fusion with pedicle screw fixation between July 2009 and July 2012. The patients' mean age at surgery was 15.79 \pm 3.21 years. All patients had at least 1 year of follow-up. Radiological parameters in the coronal and sagittal planes, including Cobb angle of the major curve, side-bending Cobb angle of the major curve, thoracic kyphosis (TK), correction rates, and screw density, were measured and analyzed. Screw densities (calculated as number of screws per fusion segment $\times 2$ ) of $<0.60$ and $\geq 0.60$ were defined as low and high density, respectively. Titanium rods of $5.5 \mathrm{~mm}$ and $6.35 \mathrm{~mm}$ diameter were defined as low and high stiffness, respectively. Patients were divided into 4 groups based on the type of rod and density of screw placement that had been used: Group A, low-stiffness rod with low density of screw placement; Group B, low-stiffness rod with high density of screw placement; Group C, high-stiffness rod with low density of screw placement; Group D, high-stiffness rod with high density of screw placement.

RESULTS The mean coronal correction rate of the major curve, for all 77 patients, was $(81.45 \% \pm 7.51 \%)$, and no significant difference was found among the 4 groups $(p>0.05)$. Regarding sagittal plane correction, Group A showed a significant decrease in TK after surgery $(p<0.05)$, while Group D showed a significant increase $(p<0.05)$; Group B and $C$ showed no significant postoperative changes in TK $(p>0.05)$. The TK restoration rate was highest in Group D and lowest in Group A (A, $-39.32 \% \pm 7.65 \%$; B, $-0.37 \% \pm 8.25 \%$; C, $-4.04 \% \pm 6.77 \%$; D, 37.59\% $\pm 8.53 \%$ ). Screw density on the concave side was significantly higher than that on the convex side in all the groups $(p<0.05)$.

CONCLUSIONS For flexible main thoracic curve AIS, both rods with high stiffness and those with low stiffness combined with high or low screw density could provide effective correction in the coronal plane; rods with high stiffness along with high screw density on the concave side could provide better outcome with respect to sagittal TK restoration.

http://thejns.org/doi/abs/10.3171/2014.10.SPINE1496

KEY WORDS adolescent idiopathic scoliosis; thoracic kyphosis; correction rate; rod stiffness; implant density

$\mathrm{A}$ DOLESCENT idiopathic scoliosis (AIS) is defined as 3-dimensional deformity with a structural, lateral, rotated curvature of the spine that arises in otherwise healthy children at or around puberty. ${ }^{40}$ Epidemiological studies estimate that AIS affects $1 \%-3 \%$ of the population. ${ }^{13,29}$ Main thoracic curve scoliosis, typically represented by Lenke Type 1 scoliosis, is the most common type of AIS. ${ }^{20}$

The main goals of operative treatment for AIS are to prevent further curve progression, obtain a balanced spine, and correct the deformity in coronal, sagittal, and transverse planes. ${ }^{40}$ The rate of correction of the major curve

ABBREVIATIONS AIS = adolescent idiopathic scoliosis; $\mathrm{LL}=$ lumbar lordosis; $\mathrm{PI}=$ pelvic incidence; $\mathrm{PT}=$ pelvic tilt; $\mathrm{SS}=$ sacral slope; $\mathrm{SVA}=$ sagittal vertical axis; $\mathrm{TK}=$ thoracic kyphosis; TLK = thoracolumbar kyphosis.

SUBMITTED February 1, 2014. ACCEPTED October 8, 2014.

INCLUDE WHEN CITING Published online December 19, 2014; DOI: 10.3171/2014.10.SPINE1496.

DISCLOSURE This work was partially supported by the Outstanding Young Investigator Support Program of The First Affiliated Hospital, Sun Yat-sen University awarded to Dr. Hui Liu.

* Drs. Liu and Z. Li contributed equally to this work. 
in the coronal plane has long been considered as the most important parameter for evaluation of treatment outcomes. However, the sagittal alignment and its change after surgery has gained more and more attention, especially when evidence suggests that correction of the coronal plane and the transverse plane using segmental pedicle screws comes at the cost of thoracic kyphosis (TK) sacrifice. ${ }^{27,35}$ Thoracic hypokyphosis is a well-acknowledged characteristic of sagittal alignment of AIS patients in previous studies. ${ }^{26,42}$ Even though there is insufficient evidence showing that it affects the quality of life of patients with AIS in the short term, a further decrease of TK after surgery is associated with increased risk of adjacent-segment disease and is a potential cause of compensatory decrease in lumbar lordosis and related adverse consequences, including disc degeneration, positive sagittal balance, back pain, and related poor quality of life with age..$^{11,12,14}$ It is reasonable to pay attention to TK restoration during surgery for main thoracic curve AIS.

Many factors can affect the correction outcomes of AIS., ${ }^{7,27}$ Curve magnitude, points of fixation, selection of instrumented level, and especially curve flexibility have been reported to be of great importance. ${ }^{22,32}$ Implant density is a focus of recent studies focuses due to the high economic cost and related complications. ${ }^{16,43}$ Inconsistent results have been reported regarding the correlation between screw density and correction outcomes. . $^{3,10,16,38 ~} \mathrm{Al}$ though most surgeons would agree that placing 2 pedicle screws at every level fused is usually unnecessary for coronal curve correction, $4,7,17,21,25$ the optimal implant density remains unknown. Especially when the sagittal plane has to be taken into consideration, to the best of our knowledge, insufficient evidence of optimal implant density is available to help with decision making.

Rod biomechanical properties represent another important factor influencing correction outcomes. Theoretically, a larger and stiffer rod would have greater ability for correction in the coronal and sagittal planes, based on biomechanical studies. ${ }^{5,16,36}$ However, results from different clinical studies have not been in accordance. For coronal plane correction, insufficient evidence was found to support the hypothesis that better correction would be provided by high rod stiffness. ${ }^{1,9,31}$ As regards sagittal plane correction, limited data have shown that a stiffer rod could provide better TK restoration, but contradictory results have also been reported.$^{6,10}$ Optimal rod properties providing the best coronal correction and sagittal alignment control require further exploration. Moreover, since pedicle screws are fixed to the rod and the two ultimately work together as a single biomechanical construct, it would be helpful to explore whether different rod stiffnesses along with different screw densities provide different correction outcomes.

The purpose of the current study is to evaluate the effects of rod stiffness along with screw density on coronal and sagittal plane correction in patients with main thoracic curve AIS.

\section{Methods}

Approval of the institutional review board of the First
Affiliated Hospital of Sun Yat-sen University was obtained prior to the current study. All cases in which patients with main thoracic adolescent idiopathic scoliosis underwent single-stage posterior-only correction and instrumented spinal fusion with pedicle screw placement at First Affiliated Hospital of Sun Yat-sen University between July 2009 and July 2012 were retrospectively reviewed. Only cases of Lenke Type 1 main thoracic curve scoliosis were included for analysis. All patients included had at least 1 year of follow-up. Patients who underwent an anterior approach or anterior-posterior approach or were treated with other implant materials were excluded. A total of $77 \mathrm{pa}-$ tients were included (56 female and 21 male; $72.73 \%$ female). The mean duration of postoperative follow-up was $1.38 \pm 0.52$ years. The patients' mean age at surgery was $15.79 \pm 3.21$ years. Of the 77 patients, 61 had a lumbar "A" Lenke modifier, 16 had a lumbar "B" modifier, and none had "C" modifiers (Table 1).

A complete radiographic series consisting of pre- and postoperative radiographs (standing whole-spine posteroanterior and lateral view radiographs, supine right and left bending radiographs) was obtained. Radiographic data were digitized and stored by PACS (picture archiving and communication system, Shenzhen Annet Information System, China). Preoperative and 1-year postoperative parameters were measured and analyzed as previously described. ${ }^{33}$ The measured parameters included the coronal Cobb angle of the main thoracic curve, bending Cobb angle of the main thoracic curve, sagittal Cobb angle of the main thoracic curve, pelvic incidence (PI), pelvic tilt (PT), sacral slope (SS), T5-12 thoracic kyphosis (TK), thoracolumbar kyphosis (TLK), lumbar lordosis (LL), sagittal vertical axis (SVA), number of pedicle screws, and number of vertebrae fused. The following two ratios were also determined as previously described in the literature: ${ }^{3,21,24}$

Flexibility of thoracic curve $(\%)=$ (preoperative coronal Cobb angle - side-bending Cobb angle)/preoperative coronal Cobb angle $\times 100 \%$.

Immediate coronal/sagittal plane correction rate $(\%)=$ (preoperative Cobb angle - postoperative Cobb angle)/preoperative Cobb angle $\times 100 \%$.

TABLE 1. Demographic characteristics and clinical features of the 77 patients included in this study

\begin{tabular}{|c|c|}
\hline Variable & Value or Classification \\
\hline Mean age at surgery (yrs) \pm SD & $15.79 \pm 3.21$ \\
\hline \multicolumn{2}{|l|}{ Sex (no. of patients) } \\
\hline Male & 21 \\
\hline Female & 56 \\
\hline \multicolumn{2}{|l|}{ Lenke classification } \\
\hline Group A $(n=18)$ & $\begin{array}{c}1 \mathrm{~A}-\text { in } 4 \text { cases, } 1 \mathrm{AN} \text { in } 9 \text { cases, } \\
1 \mathrm{~B}-\text { in } 1 \text { case, } 1 \mathrm{BN} \text { in } 4 \text { cases }\end{array}$ \\
\hline Group B $(n=17)$ & $\begin{array}{l}1 \mathrm{~A}-\text { in } 4 \text { cases, } 1 \mathrm{AN} \text { in } 12 \text { cases, } \\
1 \mathrm{BN} \text { in } 1 \text { case }\end{array}$ \\
\hline Group C ( $n=22)$ & $\begin{array}{r}1 \mathrm{~A}-\text { in } 5 \text { cases, } 1 \mathrm{AN} \text { in } 12 \text { cases, } \\
1 \mathrm{~B}-\text { in } 2 \text { cases, } 1 \mathrm{BN} \text { in } 3 \text { cases }\end{array}$ \\
\hline Group D $(n=20)$ & $\begin{array}{r}1 \mathrm{~A}-\text { in } 4 \text { cases, } 1 \mathrm{AN} \text { in } 11 \text { cases, } \\
1 \mathrm{~B}-\text { in } 1 \text { case, } 1 \mathrm{BN} \text { in } 4 \text { cases }\end{array}$ \\
\hline
\end{tabular}


Implant density was expressed as number of screws per fusion segment $\times 2$.

Screw densities of $<0.60$ and $\geq 0.60$ were defined as low density and high density, respectively. Titanium rods of $5.5 \mathrm{~mm}$ and $6.35 \mathrm{~mm}$ diameter were defined as low stiffness and high stiffness, respectively, according to the literature. ${ }^{1,5,36}$ All cases were divided into 4 groups: Group A, low-stiffness rod with low density of screw placement; Group B, low-stiffness rod with high density of screw placement; Group C, high-stiffness rod with low density of screw placement; Group D, high-stiffness rod with high density of screw placement.

\section{Operation Technique}

All the surgeries were performed in a single medical institution by one of two senior surgeons with similar training. The main thoracic curve was treated with selective thoracic fusion. Fusion-level selection criteria were as described previously. ${ }^{8,19}$ Briefly, the upper instrumented vertebra in patients with level shoulders was to T-3 or T-4; for patients with left shoulder elevation, fixation was extended to T-2. The lowest instrumented vertebra was the lowest vertebra touched by the central sacral vertical line.

All patients underwent posterior surgery under general anesthesia with spinal cord monitoring of somatosensory evoked potentials and motor evoked potentials. The operations were performed through a standard posterior midline incision. Bilateral pedicle screws were inserted with the freehand technique with the assistance of C-arm fluoroscopy. Screw diameter and length were evaluated preoperatively by the CT scan and measured intraoperatively. Multi-axial screws were inserted at the apical area of the curve, and mono-axial screws were inserted at the other segments. The en bloc rod-rotation technique was applied for the scoliosis correction. A $30^{\circ}$ pre-contoured rod was inserted at the concave side first. The rod-contouring procedure was performed intraoperatively by the surgeons with the guidance of a pre-contoured rod model of a tangential angle of $30^{\circ}$, after the rod length was measured for each individual patient. The pre-contoured rod model was made preoperatively as described in the literature..$^{5,36}$ After the concave rod was engaged in all anchors, rod rotation instruments were attached to the rod. An assistant pushed down on the convex ribs, and the surgeon rotated the concave rod approximately $90^{\circ}$ in the direction that would reduce the rib prominence. The two maneuvers were done simultaneously. Set screws were then tightened on the concave rod, holding the curve in the position achieved..$^{17}$ A convex rod was then applied to stabilize the correction. A distraction maneuver was additionally applied on the concave side for further correction.

\section{Statistics Analysis}

Data were analyzed using SPSS 18.0 (SPSS, Inc.). Comparison was performed using 1-way ANOVA and the Wilcoxon rank-sum test. Data were presented as mean value \pm standard deviation, and $p<0.05$ was considered to indicate statistical significance.

\section{Results}

Before surgery, the overall mean value $( \pm \mathrm{SD})$ for the
Cobb angle of the end vertebrae on standing radiographs (a measure of deformity in the coronal plane as) for all 77 patients was $49.18^{\circ} \pm 13.29^{\circ}$. The mean value for flexibility of the curve was $44.38 \% \pm 20.58 \%$ based on push-prone radiographs. The mean implant density was $0.59 \pm 0.09$.

\section{Comparative Study of Coronal Correction Outcomes}

Table 2 shows the mean values for coronal flexibility and coronal plane correction in each group. No significant between-group differences were found in preoperative coronal Cobb angle, flexibility, postoperative coronal Cobb angle, or coronal correction rate.

\section{Comparative Study of Sagittal Correction Outcomes}

Table 3 shows the mean sagittal correction rates for each group before and after surgery. Group A showed a significant decrease in mean sagittal Cobb angle after surgery (preoperative Cobb $22.74^{\circ} \pm 7.10^{\circ}$ vs postoperative Cobb $\left.13.80^{\circ} \pm 5.31^{\circ}, \mathrm{p}<0.05\right)$, while Group D showed a significant increase mean sagittal Cobb angle after surgery (preoperative Cobb $22.02^{\circ} \pm 7.80^{\circ}$ vs postoperative Cobb $\left.27.08^{\circ} \pm 5.70^{\circ}, p<0.05\right)$. Groups B and C showed no significant differences in sagittal Cobb angle before and after surgery. Although there was no significant difference in mean preoperative values for sagittal Cobb angle, between-groups comparison of postoperative values showed that the mean postoperative sagittal Cobb angle for Group A $\left(13.80^{\circ} \pm 5.31^{\circ}\right)$ was significantly smaller than the corresponding values for Groups B, C, and D, and the mean postoperative value for Group $\mathrm{D}\left(27.08^{\circ} \pm 5.70^{\circ}\right)$ was significantly larger than the corresponding values for Groups A, B, and C. The sagittal correction rate was highest in Group D $(36.97 \% \pm 10.70 \%)$ and lowest in Group A $(-29.57 \% \pm 11.37 \%)$.

\section{Comparative Study of Sagittal Parameters}

Table 4 shows the mean values of sagittal parameters for each group before and after surgery. Group A showed significantly decreased TK after surgery (preoperative TK $22.36^{\circ} \pm 8.05^{\circ}$ vs postoperative TK $11.72^{\circ} \pm 3.30^{\circ}$, p < $0.05)$, while Group D showed significantly increased TK after surgery (preoperative TK $21.41^{\circ} \pm 7.99^{\circ}$ vs postoperative TK $27.31^{\circ} \pm 7.64^{\circ}, p<0.05$ ). Groups B and C showed no statistically significant differences between pre- and postoperative mean values for TK. Compared with the other groups, Group A showed a significantly lower mean postoperative TK value $\left(11.72^{\circ} \pm 3.30^{\circ}\right)$ and Group D showed a significantly greater value $\left(27.31^{\circ} \pm\right.$ $7.64^{\circ}$ ), although there were no statistically significant between-group differences in preoperative TK values. The TK restoration rate was highest in Group D and lowest in Group A (Group A, $-39.32 \% \pm 7.65 \%$; Group B, $-0.37 \%$ $\pm 8.25 \%$; Group C, $-4.04 \% \pm 6.77 \%$; Group D, $37.59 \% \pm$ $8.53 \%$ ). Group A showed significant decreased LL after surgery (preoperative LL $42.78^{\circ} \pm 12.00^{\circ}$ vs postoperative LL $37.14^{\circ} \pm 9.99^{\circ}, p<0.05$ ). No significant differences were found with respect to the other sagittal parameters (TLK, PI, PT, SS, and SVA) either between pre- and postoperative measurements or between groups. 
TABLE 2. Comparative study of coronal correction outcomes*

\begin{tabular}{ccccc}
\hline Group & Preop Cobb Angle $\left({ }^{\circ}\right)$ & Flexibility $(\%)$ & Postop Cobb Angle $\left({ }^{\circ}\right)$ & Correction Rate $(\%)$ \\
\hline All cases & $49.18 \pm 13.29$ & $44.38 \pm 20.58$ & $9.25 \pm 4.75$ & $81.45 \pm 7.51$ \\
\hline$A(n=18)$ & $51.03 \pm 16.51$ & $40.03 \pm 20.13$ & $10.13 \pm 5.23$ & $80.62 \pm 6.66$ \\
\hline$B(n=17)$ & $52.79 \pm 17.69$ & $46.91 \pm 16.67$ & $10.18 \pm 4.69$ & $80.52 \pm 6.40$ \\
\hline C $(n=22)$ & $48.86 \pm 7.90$ & $44.82 \pm 20.18$ & $9.91 \pm 4.70$ & $80.12 \pm 7.88$ \\
\hline D $(n=20)$ & $44.80 \pm 9.75$ & $45.66 \pm 24.93$ & $6.96 \pm 3.89$ & $84.44 \pm 8.37$ \\
\hline
\end{tabular}

* Values are means \pm SD. There was no statistically significant difference among the groups.

\section{Comparative Study of Concave- and Convex-Side Screw Density}

Table 5 shows comparison of concave- and convex-side screw density in each group. As might be expected given the grouping method, Groups B and D showed significantly higher total screw density. In all groups, screw density was significantly higher on the concave side than on the convex side.

\section{Discussion}

Main thoracic curve (Lenke Type 1) AIS is the most common type of AIS..$^{18}$ The main surgical goal in treating patients with this condition is to recover the trunk balance and correct the deformity. ${ }^{40}$

Major curve correction in the coronal plane has long been the main focus of AIS correction. In the current study, the mean correction rate in the coronal plane, for all 77 patients, was $81.45 \% \pm 7.51 \%$ (Table 2), which was similar to previous findings..$^{15,31,41}$ Furthermore, no significant differences in mean coronal correction rate were found among the 4 groups with different rod stiffness or screw density, suggesting that the less stiff rod $(5.5 \mathrm{~mm}$ titanium) and lower screw density $(<0.60)$ were able to provide enough coronal correction, and higher rod stiffness and screw density did not improve the coronal correction outcome. These findings were in accordance with most previous studies. ${ }^{3,21,32}$ It may be explained by the concept that curve flexibility of the deformed spine is the most important key factor determining the correction outcome in the coronal plane..$^{24,41}$ To confirm this concept with our own data, we compared curve flexibility among the 4 groups; no significant differences were found. The results of the current study indicate that for a flexible main thoracic curve, rods with high or low stiffness combined with high or low screw density could provide effective correction in the coronal plane.
Sagittal balance and related quality of life have gained increasing attention in recent years. Thoracic hypokyphosis is a main feature of sagittal alignment for most patients with Lenke Type 1 AIS. ${ }^{34,44}$ In the cases evaluated for the current study, the patients had less thoracic kyphosis than individuals without AIS, similar to reports in the literature. ${ }^{26,42}$ It has been noticed that posterior correction using segmental pedicle screw instrumentation can result in a further decrease in TK, because of various factors, including prone positioning, compressing maneuver, direct vertebral de-rotation, etc. ${ }^{23,27,30,39}$ Although so far there is insufficient evidence showing that this further decrease of TK after surgery affects the quality of life in patients treated for AIS, it may still increase the risk of adjacent-segment disease and be a potential cause of iatrogenic loss of lumbar lordosis. Adjacent-segment disease, including cervical kyphosis and junctional kyphosis proximal to the fused thoracic spine, was found to be related to TK decrease after AIS correction, especially when pedicle screw instrumentation was used. Iatrogenic loss of lumbar lordosis and related flat-back syndrome are usually discussed when the lumbar spine is involved in fusion surgery, but decrease of lumbar lordosis in the unfused lumbar spine due to TK decrease has been recently noticed, and it may be considered a different kind of iatrogenic flat back. ${ }^{27,30}$ Adverse consequences like disc degeneration, positive sagittal balance, back pain, and related loss of quality of life could be reasonably predicted with age. ${ }^{11,12,14}$ It is reasonable to pay more attention to TK restoration in order to minimize the adverse effects of its decrease when correcting the coronal deformity. ${ }^{15}$ From this point of view, the patients included in the current study who had sagittal modifiers "-" or "N" and whose preoperative TK was less than that of the normal population can be considered as the same population requiring TK maintenance or restoration.

TABLE 3. Comparative study of sagittal correction outcomes*

\begin{tabular}{|c|c|c|c|}
\hline Group & Preop Sagittal Cobb Angle $\left(^{\circ}\right)$ & Postop Sagittal Cobb Angle $\left(^{\circ}\right)$ & Correction Rate (\%) \\
\hline$A(n=18)$ & $22.74 \pm 7.10$ & $13.80 \pm 5.31 \dagger \ddagger$ & $-29.57 \pm 11.37$ \\
\hline$B(n=17)$ & $20.94 \pm 4.83$ & $19.98 \pm 6.83$ & $-0.84 \pm 8.53$ \\
\hline$C(n=22)$ & $22.56 \pm 8.96$ & $20.55 \pm 8.01$ & $-0.46 \pm 9.12$ \\
\hline$D(n=20)$ & $22.02 \pm 7.80$ & $27.08 \pm 5.70 \dagger \ddagger$ & $36.97 \pm 10.70$ \\
\hline
\end{tabular}


TABLE 4. Sagittal alignment before and after surgery*

\begin{tabular}{|c|c|c|c|c|c|c|c|c|}
\hline \multirow[b]{2}{*}{ Variable } & \multicolumn{2}{|c|}{ Group A $(n=18)$} & \multicolumn{2}{|c|}{ Group B $(n=17)$} & \multicolumn{2}{|c|}{ Group C $(n=22)$} & \multicolumn{2}{|c|}{ Group D $(n=20)$} \\
\hline & Preop & Postop & Preop & Postop & Preop & Postop & Preop & Postop \\
\hline $\operatorname{TK}\left({ }^{\circ}\right)$ & $22.36 \pm 8.05$ & $11.72 \pm 3.30 \dagger$ & $20.84 \pm 4.79$ & $20.29 \pm 6.44$ & $22.35 \pm 9.06$ & $19.33 \pm 7.94$ & $21.41 \pm 7.99$ & $27.31 \pm 7.64 \dagger$ \\
\hline TLK $\left(^{\circ}\right)$ & $6.19 \pm 9.94$ & $3.32 \pm 6.90$ & $0.02 \pm 15.04$ & $-2.97 \pm 6.12$ & $-0.93 \pm 5.81$ & $2.90 \pm 9.04$ & $2.70 \pm 5.34$ & $1.70 \pm 3.38$ \\
\hline $\mathrm{LL}\left({ }^{\circ}\right)$ & $42.78 \pm 12.00$ & $37.14 \pm 9.99 \ddagger$ & $46.25 \pm 9.62$ & $45.19 \pm 9.98$ & $44.41 \pm 10.57$ & $38.59 \pm 10.57$ & $45.87 \pm 12.19$ & $45.48 \pm 8.69$ \\
\hline $\mathrm{PI}\left({ }^{\circ}\right)$ & $40.58 \pm 13.57$ & $40.31 \pm 8.73$ & $39.79 \pm 9.83$ & $40.66 \pm 7.92$ & $39.27 \pm 8.38$ & $39.83 \pm 10.74$ & $42.93 \pm 11.82$ & $43.17 \pm 8.19$ \\
\hline $\mathrm{PT}\left({ }^{\circ}\right)$ & $9.17 \pm 8.45$ & $13.09 \pm 10.80$ & $2.29 \pm 9.06$ & $9.56 \pm 8.44$ & $6.86 \pm 11.48$ & $9.55 \pm 10.31$ & $6.23 \pm 7.51$ & $10.76 \pm 6.88$ \\
\hline $\operatorname{SS}\left({ }^{\circ}\right)$ & $32.00 \pm 8.42$ & $28.96 \pm 8.03$ & $38.74 \pm 5.88$ & $34.02 \pm 4.57$ & $33.64 \pm 7.09$ & $31.21 \pm 7.98$ & $38.23 \pm 8.73$ & $33.76 \pm 6.27$ \\
\hline $\operatorname{SVA}\left({ }^{\circ}\right)$ & $0.16 \pm 2.96$ & $-0.40 \pm 2.63$ & $0.48 \pm 2.23$ & $0.38 \pm 1.89$ & $-0.47 \pm 2.43$ & $0.45 \pm 1.82$ & $-0.60 \pm 1.82$ & $0.77 \pm 3.11$ \\
\hline
\end{tabular}

* Values represent means \pm SD.

† Significant difference for comparison to preoperative value for the same group and to postoperative values for the other 3 groups ( $p<0.05)$. The mean restoration rate for Group D $(37.59 \% \pm 8.53 \%)$ was significantly greater than the restoration rates for the other 3 groups, and the restoration rate for Group A (-39.32\% $\pm 7.65 \%)$ was significantly lower $(p<0.05)$.

$\ddagger$ Significant difference for comparison to preoperative value for the same group and to postoperative values for the other 3 groups $(p<0.05)$.

The effect of implant density on sagittal plane correction and TK restoration has been reported in only a few studies, and the results have been inconsistent. ${ }^{3,25,32}$ Quan and Gibson ${ }^{32}$ and Bharucha et al. ${ }^{3}$ showed no correlation between screw density and sagittal plane correction. On the other hand, Suk et al. ${ }^{37}$ reported good TK restoration in both high- and low-density groups, whereas Clements et al. ${ }^{6}$ reported decreased TK with increased implant density. In the current study, higher screw density in the setting of the same rod stiffness provided better TK restoration than low screw density (Group A vs Group B; Group C vs Group D) (Table 4), suggesting that screw density had a positive effect on TK preservation. Since the rod rotation maneuver was performed using the concave rod, we further investigated if the screw density on the concave side differed among the groups. Our results showed higher concave-side screw density in both groups with high- and low-stiffness rods, but no significant differences of convex-side screw density between these two groups. Our results showed that the screw density was significantly higher on the concave side than on the convex side in all 4 groups, but there was no significant difference in convex-side screw density between patients treated with lowstiffness rods and those treated with high-stiffness rods (i.e., Groups A and B vs Groups C and D). This finding indicated that concave-side rather than convex-side screw density had an impact on TK restoration. It supports the importance of concave-side implant density on TK restoration reported by Cidambi et al. ${ }^{5}$ and La Rosa et al. ${ }^{15} \mathrm{~A}$ possible explanation could be that the increased friction at the screw-rod interface that occurs with higher screw density would prevent flattening of the contoured rod in the sagittal plane after rod rotation (Fig. 1).

Rod stiffness determines the ability of a rod to exert corrective force and retain the pre-contoured shape to achieve and maintain deformity correction. ${ }^{1,36}$ However, most studies were biomechanically based, and only limited clinical studies have reported the effect of rod stiffness on sagittal correction..$^{2,28}$ Cidambi et al. ${ }^{5}$ found that the shape of the pre-contoured rod is associated with TK preservation; Abul-Kasim et al. ${ }^{1}$ indicated that increased rod stiffness could improve TK restoration. Similarly, results of the current study showed that in the setting of similar screw density, a stiffer rod provided better outcome with respect to TK restoration (Group A vs Group B, Group C vs Group D; Table 4). Rod stiffness is basically determined by the rod material and diameter. However, the number of pedicle screws attached to the rod and the distance between pedicle screws also affect the overall rod-screw construct stiffness. ${ }^{36}$ This explains our result that higher screw density with a less stiff rod construct could achieve similar TK restoration to less screw density with a stiffer rod construct (Group B vs Group C, Table 4).

In the current correction system, by using the concaveside en bloc rod rotation maneuver for the correction, the pre-contoured curvature of the rod is to be rotated from a coronal plane to a sagittal plane (total rotation of approximately $90^{\circ}$ ). During this procedure, the scoliotic (in the coronal plane) spine is supposed to follow the shape of the rod and become straight (in the coronal plane) and more kyphotic (in the sagittal plane), according to the design of this maneuver. However, the deformed spine tends to

TABLE 5. Comparison of concave- and convex-side screw density

\begin{tabular}{cccc}
\hline Group & Concave & Convex & Total \\
\hline$A(n=18)$ & $0.61 \pm 0.09 \dagger$ & $0.47 \pm 0.07$ & $0.54 \pm 0.03$ \\
\hline$B(n=17)$ & $0.79 \pm 0.19 \dagger^{*}$ & $0.58 \pm 0.20$ & $0.68 \pm 0.07^{*}$ \\
\hline$C(n=22)$ & $0.56 \pm 0.11 \dagger$ & $0.47 \pm 0.14$ & $0.51 \pm 0.05$ \\
\hline$D(n=20)$ & $0.74 \pm 0.14 \dagger^{*}$ & $0.55 \pm 0.14$ & $0.66 \pm 0.06^{*}$ \\
\hline
\end{tabular}

* Significantly different from values for Group A and $C(p<0.05)$.

$\dagger$ Significantly different from value for convex side $(p<0.05)$. 


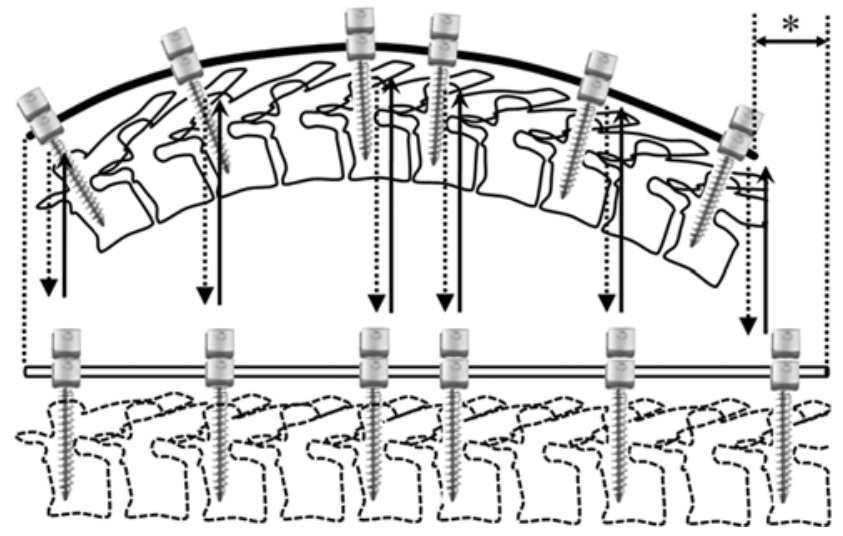

FIG. 1. Diagram illustrating the two counter forces that determine the final correction outcome. Solid arrows represent corrective force exerted from the stiffness of the rod; dotted arrows represent resistant force from the deformed spine. These two forces act on each other via the pedicle screws and convert into pullout force. The stiffer the rod, the more corrective force is exerted by the rod. If this corrective force is stronger than the resistant force from the spine, and greater than the pullout force from the screw-bone interaction, the corrective force would be applied on the spine and the spine would follow the shape of the rod. This diagram also illustrates the flattening of the rod if resistant force is greater than corrective force (dotted line and asterisk).

maintain its original shape due to resistant forces generating from the connecting elements (facets, intervertebral discs, rib cage, deformed and fused segments, soft tissue, etc.) and attempts to make the rod follow the shape of the spine (curved in the coronal plane and less kyphotic in the sagittal plane). Theoretically, it is these two counter forces that determine the final correction outcome. The former one is the corrective force exerted from the stiffness of the rod; the later and opposite one is the resistant force from the deformed spine. The two forces acting on each other through the anchoring screws are converted into the pullout force. The stiffer the rod, the more corrective force it exerts. If this corrective force is stronger than the resistant force from the spine and greater than the pullout force from the screw-bone interaction, the spine will follow the shape of the rod. If, on the other hand, the resistant force from the spine is greater than the corrective force, the contoured rod will follow the shape of the spine, resulting in insufficient sagittal plane correction (Fig. 1). Since pullout forces are significantly reduced by the addition of anchor points, it is reasonable to assume that more screws are needed when a pre-contoured rod with high stiffness is used to achieve better TK restoration. ${ }^{5}$ This explains our finding that both screw density and rod stiffness affected the TK restoration outcome. In the current study, a highstiffness rod with high screw density (Group D) provided better postoperative sagittal correction by providing better biomechanical properties to maintain the pre-contoured rod shape. As a result, the mean postoperative TK using this construct was close to the pre-contoured value $\left(26.26^{\circ}\right.$ vs $30^{\circ}$ ). A low-stiffness rod with high screw density and a high-stiffness rod with low screw density was able to retain the preoperative TK, whereas the combination of a low-stiffness rod and low density of screw placement was not sufficient to prevent postoperative TK decrease.
In clinical practice, when using the concave-side en bloc rod rotation maneuver to correct a main thoracic curve AIS, rods with different stiffness along with different screw density could be considered. Since the use of a stiffer rod with higher screw density on the concave side can provide effective correction in the coronal plane and provide a higher corrective force to achieve and maintain better sagittal TK restoration, it is a reasonable choice for a relatively more rigid curve with thoracic hypokyphosis or even lordosis. With higher screw density, there should be less possibility of screw pullout or implant failure, and a protective procedure like sequential tightening of set screws from the ends to the middle could be used. ${ }^{5,15}$ For a relatively more flexible curve with normal TK, a less stiff rod with higher screw density or a stiffer rod with lower screw density on the concave side can be chosen based on the bone quality and anatomical risk of screw misplacement. For a relatively more flexible curve with thoracic hyperkyphosis, a less stiff rod with low screw density combined with certain release procedure for the posterior column may be used to obtain effective coronal correction and, meanwhile, hyperkyposis correction. As regards the increased financial cost, surgical time, and risk of implant-related complications associated with greater screw density, using fewer screws in the convex side could be considered, as this should not affect the correction outcome.

Limitations of the current study include the nonprospective controlled design, inclusion of only patients with main thoracic curve kyphosis, lack of long-term followup, and small sample size. Due to the limited sample size, analysis of subgroups with different sagittal modifiers could not be conducted in the current study. Patients with a sagittal modifier " + " represent a subset requiring different management of TK and are not included in the current study; a future study focusing on these patients could be performed separately. Biomechanical studies and a prospective randomized controlled study with a larger sample size are further needed to confirm the preliminary observations and theoretical hypothesis of the current study.

\section{Conclusions}

For flexible main thoracic curve AIS, both rods with high and low stiffness, combined with high or low screw density can provide effective correction outcome in the coronal plane; use of a rod with high stiffness along with high screw density in the concave side may provide a better outcome of sagittal thoracic kyphosis (TK) restoration.

\section{References}

1. Abul-Kasim K, Karlsson MK, Ohlin A: Increased rod stiffness improves the degree of deformity correction by segmental pedicle screw fixation in adolescent idiopathic scoliosis. Scoliosis 6:13, 2011

2. Belmont PJ Jr, Polly DW Jr, Cunningham BW, Klemme WR: The effects of hook pattern and kyphotic angulation on mechanical strength and apical rod strain in a long-segment posterior construct using a synthetic model. Spine (Phila Pa 1976) 26:627-635, 2001

3. Bharucha NJ, Lonner BS, Auerbach JD, Kean KE, Trobisch PD: Low-density versus high-density thoracic pedicle screw 
constructs in adolescent idiopathic scoliosis: do more screws lead to a better outcome? Spine J 13:375-381, 2013

4. Bridwell KH, Hanson DS, Rhee JM, Lenke LG, Baldus C, Blanke K: Correction of thoracic adolescent idiopathic scoliosis with segmental hooks, rods, and Wisconsin wires posteriorly: it's bad and obsolete, correct? Spine (Phila Pa 1976) 27:2059-2066, 2002

5. Cidambi KR, Glaser DA, Bastrom TP, Nunn TN, Ono T, Newton PO: Postoperative changes in spinal rod contour in adolescent idiopathic scoliosis: an in vivo deformation study. Spine (Phila Pa 1976) 37:1566-1572, 2012

6. Clements DH, Betz RR, Newton PO, Rohmiller M, Marks MC, Bastrom T: Correlation of scoliosis curve correction with the number and type of fixation anchors. Spine (Phila Pa 1976) 34:2147-2150, 2009

7. de Jonge T, Dubousset JF, Illés T: Sagittal plane correction in idiopathic scoliosis. Spine (Phila Pa 1976) 27:754-760, 2002

8. Edwards CC II, Lenke LG, Peelle M, Sides B, Rinella A, Bridwell KH: Selective thoracic fusion for adolescent idiopathic scoliosis with $\mathrm{C}$ modifier lumbar curves: 2- to 16-year radiographic and clinical results. Spine (Phila Pa 1976) 29:536-546, 2004

9. Huang TH, Ma HL, Wang ST, Chou PH, Ying SH, Liu CL, et al: Does the size of the rod affect the surgical results in adolescent idiopathic scoliosis? $5.5-\mathrm{mm}$ versus $6.35-\mathrm{mm}$ rod. Spine J 14:1545-1550, 2014

10. Hwang CJ, Lee CK, Chang BS, Kim MS, Yeom JS, Choi JM: Minimum 5-year follow-up results of skipped pedicle screw fixation for flexible idiopathic scoliosis. Clinical article. J Neurosurg Spine 15:146-150, 2011

11. Hwang SW, Samdani AF, Tantorski M, Cahill P, Nydick J, Fine A, et al: Cervical sagittal plane decompensation after surgery for adolescent idiopathic scoliosis: an effect imparted by postoperative thoracic hypokyphosis. Clinical article. J Neurosurg Spine 15:491-496, 2011

12. Ilharreborde B, Morel E, Mazda K, Dekutoski MB: Adjacent segment disease after instrumented fusion for idiopathic scoliosis: review of current trends and controversies. J Spinal Disord Tech 22:530-539, 2009

13. Kesling KL, Reinker KA: Scoliosis in twins. A meta-analysis of the literature and report of six cases. Spine (Phila Pa 1976) 22:2009-2015, 1997

14. Kim YJ, Bridwell KH, Lenke LG, Glattes CR, Rhim S, Cheh G: Proximal junctional kyphosis in adult spinal deformity after segmental posterior spinal instrumentation and fusion: minimum five-year follow-up. Spine (Phila Pa 1976) 33:2179-2184, 2008

15. La Rosa G, Giglio G, Oggiano L: The Universal Clamp hybrid system: a safe technique to correct deformity and restore kyphosis in adolescent idiopathic scoliosis. Eur Spine J 22 (Suppl 6):S823-S828, 2013

16. Larson AN, Aubin CE, Polly DW Jr, Ledonio CG, Lonner BS, Shah SA, et al: Are more screw better? A systematic review of anchor density and curve correction in adolescent idiopathic scoliosis. Spine Deformity 1:237-247, 2013

17. Lee SM, Suk SI, Chung ER: Direct vertebral rotation: a new technique of three-dimensional deformity correction with segmental pedicle screw fixation in adolescent idiopathic scoliosis. Spine (Phila Pa 1976) 29:343-349, 2004

18. Lenke LG, Betz RR, Clements D, Merola A, Haher T, Lowe $\mathrm{T}$, et al: Curve prevalence of a new classification of operative adolescent idiopathic scoliosis: does classification correlate with treatment? Spine (Phila Pa 1976) 27:604-611, 2002

19. Lenke LG, Bridwell KH, Baldus C, Blanke K: Preventing decompensation in King type II curves treated with CotrelDubousset instrumentation. Strict guidelines for selective thoracic fusion. Spine (Phila Pa 1976) 17 (8 Suppl):S274S281, 1992
20. Lenke LG, White DK, Kemp JS, Bridwell KH, Blanke KM, Engsberg JR: Evaluation of ventilatory efficiency during exercise in patients with idiopathic scoliosis undergoing spinal fusion. Spine (Phila Pa 1976) 27:2041-2045, 2002

21. Li M, Shen Y, Fang X, Ni J, Gu S, Zhu X, et al: Coronal and sagittal plane correction in patients with Lenke 1 adolescent idiopathic scoliosis: a comparison of consecutive versus interval pedicle screw placement. J Spinal Disord Tech 22:251-256, 2009

22. Lu DS, Luk KD, Lu WW, Cheung KM, Leong JC: Spinal flexibility increase after chymopapain injection is dose dependent: a possible alternative to anterior release in scoliosis. Spine (Phila Pa 1976) 29:123-128, 2004

23. Luhmann SJ, Lenke LG, Erickson M, Bridwell KH, Richards BS: Correction of moderate ( $<70$ degrees) Lenke 1A and 2A curve patterns: comparison of hybrid and all-pedicle screw systems at 2-year follow-up. J Pediatr Orthop 32:253-258, 2012

24. Luk KD, Cheung WY, Wong Y, Cheung KM, Wong YW, Samartzis D: The predictive value of the fulcrum bending radiograph in spontaneous apical vertebral derotation in adolescent idiopathic scoliosis. Spine (Phila Pa 1976) 37:E922E926, 2012

25. Luk KD, Lu DS, Cheung KM, Wong YW: A prospective comparison of the coronal deformity correction in thoracic scoliosis using four different instrumentations and the fulcrum-bending radiograph. Spine (Phila Pa 1976) 29:560563,2004

26. Mac-Thiong JM, Roussouly P, Berthonnaud E, Guigui P: Sagittal parameters of global spinal balance: normative values from a prospective cohort of seven hundred nine Caucasian asymptomatic adults. Spine (Phila Pa 1976) 35:E1193E1198, 2010

27. Newton PO, Yaszay B, Upasani VV, Pawelek JB, Bastrom TP, Lenke LG, et al: Preservation of thoracic kyphosis is critical to maintain lumbar lordosis in the surgical treatment of adolescent idiopathic scoliosis. Spine (Phila Pa 1976) 35:1365-1370, 2010

28. Orchowski J, Polly DW Jr, Klemme WR, Oda I, Cunningham $\mathrm{B}$ : The effect of kyphosis on the mechanical strength of a long-segment posterior construct using a synthetic model. Spine (Phila Pa 1976) 25:1644-1648, 2000

29. Parent S, Newton PO, Wenger DR: Adolescent idiopathic scoliosis: etiology, anatomy, natural history, and bracing. Instr Course Lect 54:529-536, 2005

30. Potter BK, Lenke LG, Kuklo TR: Prevention and management of iatrogenic flatback deformity. J Bone Joint Surg Am 86-A:1793-1808, 2004

31. Prince DE, Matsumoto H, Chan CM, Gomez JA, Hyman JE, Roye DP Jr, et al: The effect of rod diameter on correction of adolescent idiopathic scoliosis at two years follow-up. J Pediatr Orthop 34:22-28, 2014

32. Quan GM, Gibson MJ: Correction of main thoracic adolescent idiopathic scoliosis using pedicle screw instrumentation: does higher implant density improve correction? Spine (Phila Pa 1976) 35:562-567, 2010

33. Roussouly P, Pinheiro-Franco JL: Biomechanical analysis of the spino-pelvic organization and adaptation in pathology. Eur Spine J 20 (Suppl 5):609-618, 2011

34. Schlösser TP, Shah SA, Reichard SJ, Rogers K, Vincken KL, Castelein RM: Differences in early sagittal plane alignment between thoracic and lumbar adolescent idiopathic scoliosis. Spine J 14:282-290, 2014

35. Schmidt C, Liljenqvist U, Lerner T, Schulte TL, Bullmann V: Sagittal balance of thoracic lordoscoliosis: anterior dual rod instrumentation versus posterior pedicle screw fixation. Eur Spine J 20:1118-1126, 2011

36. Serhan H, Mhatre D, Newton P, Giorgio P, Sturm P: Would $\mathrm{CoCr}$ rods provide better correctional forces than stainless 
steel or titanium for rigid scoliosis curves? J Spinal Disord Tech 26:E70-E74, 2013

37. Suk SI, Lee CK, Kim WJ, Chung YJ, Park YB: Segmental pedicle screw fixation in the treatment of thoracic idiopathic scoliosis. Spine (Phila Pa 1976) 20:1399-1405, 1995

38. Tao F, Zhao Y, Wu Y, Xie Y, Li M, Lu Y, et al: The effect of differing spinal fusion instrumentation on the occurrence of postoperative crankshaft phenomenon in adolescent idiopathic scoliosis. J Spinal Disord Tech 23:e75-e80, 2010

39. Watanabe K, Nakamura T, Iwanami A, Hosogane N, Tsuji T, Ishii K, et al: Vertebral derotation in adolescent idiopathic scoliosis causes hypokyphosis of the thoracic spine. BMC Musculoskelet Disord 13:99, 2012

40. Weinstein SL, Dolan LA, Cheng JC, Danielsson A, Morcuende JA: Adolescent idiopathic scoliosis. Lancet 371:15271537,2008

41. Winter RB, Lonstein JE, Denis F: How much correction is enough? Spine (Phila Pa 1976) 32:2641-2643, 2007

42. Winter RB, Lonstein JE, Denis F: Sagittal spinal alignment: the true measurement, norms, and description of correction for thoracic kyphosis. J Spinal Disord Tech 22:311-314, 2009

43. Yang S, Jones-Quaidoo SM, Eager M, Griffin JW, Reddi V, Novicoff W, et al: Right adolescent idiopathic thoracic curve (Lenke $1 \mathrm{~A}$ and B): does cost of instrumentation and implant density improve radiographic and cosmetic parameters? Eur Spine J 20:1039-1047, 2011

44. Yong Q, Zhen L, Zezhang Z, Bangping Q, Feng Z, Tao W, et al: Comparison of sagittal spinopelvic alignment in Chinese adolescents with and without idiopathic thoracic scoliosis. Spine (Phila Pa 1976) 37:E714-E720, 2012

\section{Author Contributions}

Conception and design: Zheng, Z Li. Acquisition of data: Zheng, Liu, Z Li, S Li, Zhang. Analysis and interpretation of data: all authors. Drafting the article: all authors. Critically revising the article: Zheng, Yang, Wang, X Li. Reviewed submitted version of manuscript: Zheng, S Li, Wang. Approved the final version of the manuscript on behalf of all authors: Zheng. Statistical analysis: Zheng, Yang. Administrative/technical/material support: Zheng. Study supervision: Zheng.

\section{Supplemental Information}

Current Affiliation

Dr. Zhang: The Fifth Affiliated Hospital, Sun Yat-sen University, Zhuhai, China.

\section{Correspondence}

Zhaomin Zheng, Department of Spine Surgery, The First Affiliated Hospital, Sun Yat-sen University, No. 58, Zhongshan 2nd Rd., Guangzhou 510080, China. email: zhengzm1@163.com. 